\title{
Review on Recent Trends \& Optimisation in Heat Treatment
}

\author{
${ }^{1}$ Prof. Gaurav D. Sonawane, ${ }^{1}$ Prof. Shrikant U Gunjal \\ ${ }^{1}$ Asst. Professor, Mechanical Engg. Dept, Sandip Foundation, SITRC, Mahiravani, Trimbak Road, Nashik- \\ 422213, Maharashtra, India.
}

\begin{abstract}
Progress and productivity are the keys to survival, and green manufacturing is a prime source for innovation. In the past few decades a slow rate of development in heat treatment has been done, due to its ignorance and poor understandability. Recently market has started eyeing on heat treatment and surface engineering as the most vital departments were lot of research and development is to be done because of the continuous demand of energy efficient, environmental friendly, optimum cost process. Heat treatment and surface engineering are the key technologies to enhance effective use of materials applied for automobiles, aerospace and weapons. After understanding, such a vital role of heat treatment many advanced steps like vacuum heat treating, development in quenching media, laser heat treating, electromagnetic processing, intensive quenching have been taken which has resulted in 30\% increase in case depth, 25-30\% reduction in process time, $30 \%$ reduction in energy consumption and purely environmental friendly process. This paper presents a short overview of new trends of heat treatment and process optimisation with its future technical possibilities.
\end{abstract}

Keywords: process optimisation, environmental friendly, future in 2020

\section{Introduction}

Heat treatment has changed beyond recognition since the first simple annealing and hardening cycles were discovered empirically hundreds of years ago. These changes have been driven by a better understanding of the underlying science, increasing demand for products and quality requirements, and latterly, social factors such as environmental considerations. In addition, the market has been shaped by technological developments, such as the changing use of materials and advances in manufacturing techniques, which have opened up new opportunities. Pointing out at the new heat treatment process which is vacuum heat treatment, intensive quench, direct forge quench with poly alkaline glycol, electromagnetic processing which have improved the quality and cost with reduction in cycle time and proving environmental friendly [1].

Vacuum heat treatment has been looked as a boon to the heat treat industry saving 33-50\% of cycle time as compared to the atmospheric process. While, other development in quenching media has increased case depth by around $30 \%$ along with surface finish. The sparking method electromagnetic processing is one of the challenging technologies where a great deal of success like acceleration of the transformation phase has been achieved and hence enhancement in the property like yield strength of steel by 10-15\%.These all methods have also proved as a step towards the fulfilling of social duty, that of designing environmental friendly process [2].

\section{Advancement in Conventional Heat Treating}

The concept of heat treatment means the controlled application of time, temperature, and atmosphere to produce a predictable change in the microstructure of a material.

Vacuum heat treatment process was introduced in the 1970's, and since than last decade has seen double-digit growth and development in vacuum heat treatment industry. Vacuum processing is growing more than any other technology, due to its large part to the demand for high quality, precision and repeatability of part performance in ever more sophisticated and demanding service applications.

Vacuum heat treatment types:

- Vacuum carburising

- Vacuum nitriding

- Vacuum carbo-nitriding

- Vacuum brazing

- Vacuum sintering 


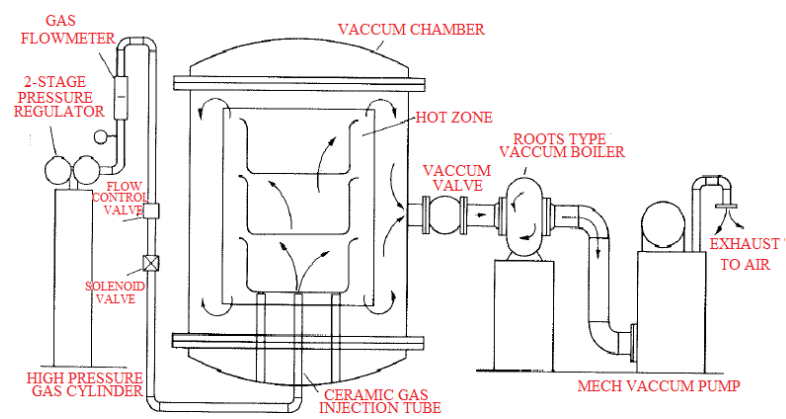

Fig. 1. Vacuum carburising furnace

\section{A. Vacuum carburising with high pressure gas quench}

Vacuum carburizing induces a high carbon transfer, which leads to a reduction of process time compared with atmospheric gas carburizing. The use of oxygen free hydrocarbons prevents surface oxidation on the part surface.

High carburizing temperatures up to $1,000^{\circ} \mathrm{C}$ and higher lead to additional productivity. However, there is the risk of grain growth during high-temperature carburizing that can increase the potential for distortion by the formation of a mixed-grain area in the material. But recent developments in the steel industry have shown that it is possible to prevent grain growth at temperatures higher than $1,050^{\circ} \mathrm{C}$ by using steels with alloying elements such as $\mathrm{Nb}, \mathrm{Ti}$ and $\mathrm{Al}$.

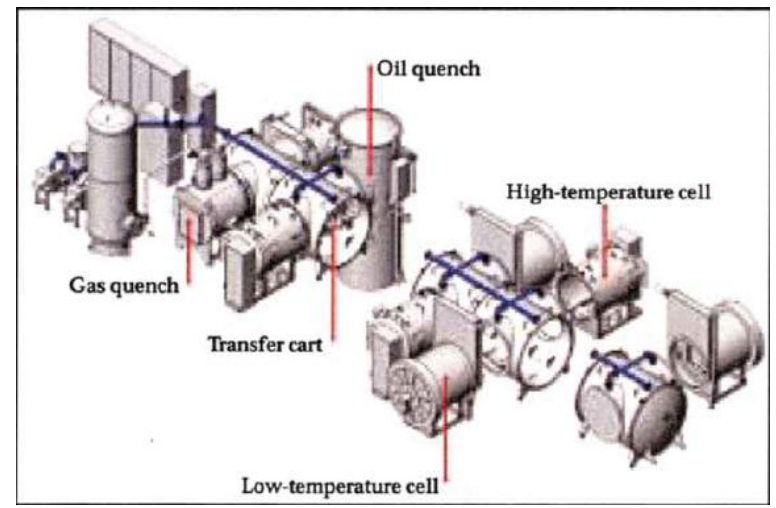

Fig. 2 Vacuum carburising chamber for

High production

High-pressure gas quenching as shown in Fig. 2 is a dry quenching method that has many important ecological and economic advantages when compared with liquid quenching. The quenching gases used, such as nitrogen and helium, are inert and leave no parts residue, negating the need for additional investment in washing machines or fi re monitoring devices.

But the most significant advantage of gas quenching is a very uniform heat transfer. The predictability of movement during quenching is more certain and uniform throughout the load, thereby reducing hard machining costs. High-pressure gas quenching was successfully introduced for the heat treatment of parts in the automotive industry some years ago, and numerous investigations have shown that distortion can be significantly controlled as opposed to liquid quenching [3]. 


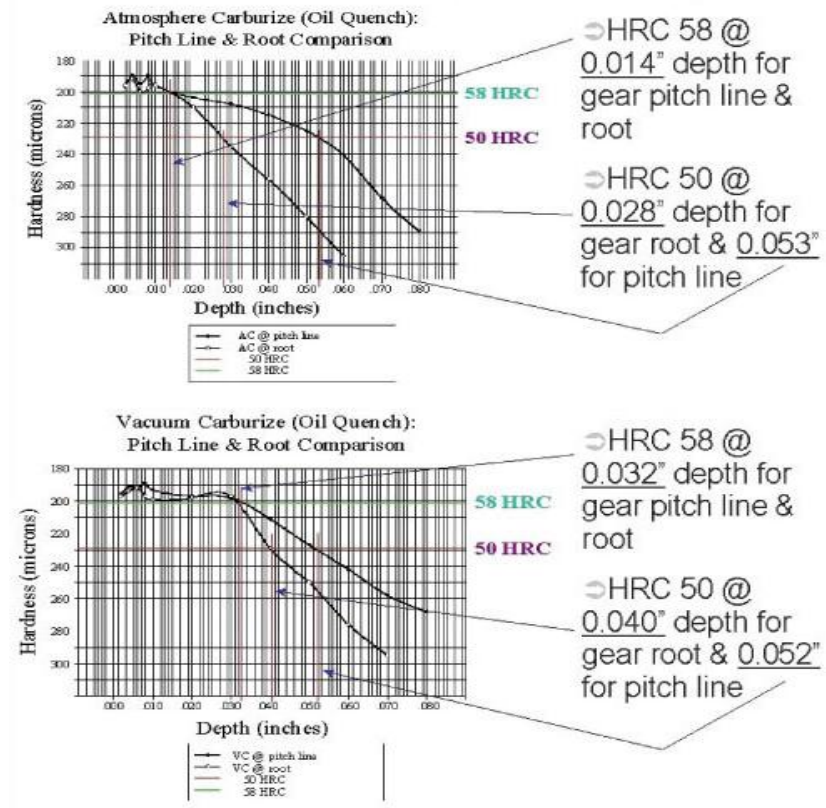

Fig. 3 Graph of atmospheric vs vacuum carburising [5]

\section{B. Vacuum carbonitriding with high pressure gas quench}

It is a thermal process of simultaneously diffusing both carbon and nitrogen into ferrous alloys under partial pressure. This leads to an extremely hard and wear resistant surface. Vacuum carbonitriding is a significant improvement over conventional gas carbonitriding. The process contains all of the inherent benefits of vacuum carburizing, but also has the additional benefit of precise computer control of surface ammonia content. Furthermore, this process does not require any additional refractory burn-outs so not only is the end product of higher quality, but it is often less expensive than with competing conventional gas processes. Carbonitriding gives lesser distortion as compared to carburising.

Carbonitriding is a modification of the carburizing process, not a form of nitriding. This modification consists of introducing ammonia into the carburizing atmosphere in order to add nitrogen to the carburized case as it is being produced. Examples of gear steels that are commonly carbonitrided include SAE 1018, 1117, and 12L14.Typically, carbonitriding is done at a lower temperature than carburizing, between 700 and $900^{\circ} \mathrm{C}(1300$ and $1650^{\circ} \mathrm{F}$ ), and for a shorter time. Combine this with the fact that nitrogen inhibits the diffusion of carbon, and what generally results is a shallower case than is typical for carburized parts. A carbonitrided case is usually between $0.075-0.75 \mathrm{~mm}(0.003$ "-0.030") deep [4].

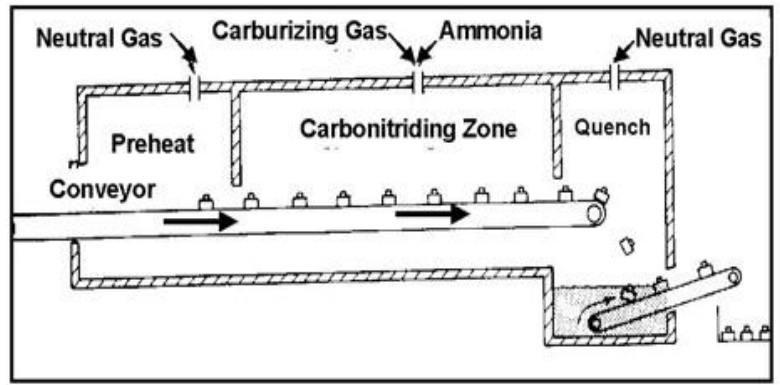

\section{Conveyor Hearth Carbonitriding}

Fig. 4 Conveyor hearth carbonitriding [5]

Case depth control: Effective case depth ranges for vacuum-carburized parts routinely vary from 0.010 to 0.250 in. $(0.25$ to $6.35 \mathrm{~mm})$. Maximum case variation within a load can be held to within 0.005 in. $(0.125$ $\mathrm{mm}$ ), and this is routine for aerospace and motorsports components. In one particular vacuum carbonitriding application, as from Fig. 3 the specification called out an extremely shallow case, 0.0005 to 0.0025 in., and the final part variation achieved was 0.0018 to 0.0022 in, which is nearly about $30 \%$ more than the atmospheric carburising/carbonitriding [5]. 
Table I Examples of vacuum heat treating applications and industries.

\begin{tabular}{|l|l|}
\hline \multicolumn{1}{|c|}{ Application } & \multicolumn{1}{c|}{ Typical Industry } \\
\hline $\begin{array}{l}\text { Batteries, Fuel Cells, Solar } \\
\text { Power Devices }\end{array}$ & $\begin{array}{l}\text { Automotive, Industrial Products (Power } \\
\text { Generation) }\end{array}$ \\
\hline $\begin{array}{l}\text { Biomedical Implants and } \\
\text { Devices }\end{array}$ & Industrial Products \\
\hline $\begin{array}{l}\text { Engine and land based turbine } \\
\text { blades }\end{array}$ & Aerospace, Industrial products \\
\hline Fuel systems & Automotive \\
\hline Nuclear fuel elements & Industrial Products \\
\hline $\begin{array}{l}\text { Transmission Components } \\
\text { (Powertrain) }\end{array}$ & Automotive, Aerospace \\
\hline Sensors & Automotive, Aerospace \\
\hline Tools and accessories & Industrial Products \\
\hline Light guides & Industrial Products \\
\hline
\end{tabular}

\section{Intensive quenching system (IQS)}

\section{Advances in Quenching Technology}

1.1 IQ-1 Intensive Quenching Method: The IQ-1 quenching method is a two-step cooling process. It is used for medium-alloy and high-alloy steel parts. It takes place in three stages, detailed in Fig. 5. At the first stage of quenching, steel parts cool slowly from the austenitizing temperature down to the martensite start temperature Ms (for example: in hot oil or in high-concentration water/polymer solutions). There is an insignificant temperature gradient throughout the part cross-section within this slow cooling stage. Therefore, the initial temperature throughout the entire part can be assumed equal to the temperature Ms at the beginning of the second stage of cooling. The second stage of quenching is very intensive and it takes place within the temperature range of martensite transformations. Water jets or directed streams of quenchants around the steel part provide high cooling rates. Intensive cooling results in the formation of high compressive stresses on the part surface. These compressive surface stresses "fix" the low part distortion obtained in the first, slow cooling stage, and also provide additional strengthening or "super strengthening" of material.

However, a shortcoming of IQ-1 process is that a) oils or high-concentration polymers are used at the first stage of cooling, and b) the second stage of cooling is conducted in a separate chamber. The use of quench oils or high concentration of polymers in water (20\% to $24 \%)$ considerably reduces the hardening capacity as a quenchant for steel parts. The necessity of a second cooling chamber complicates the hardening process and makes it difficult to maintain in practice and more expensive. A more advanced steel quenching method, IQ-2 has been developed to alleviate the shortcomings of IQ-1.

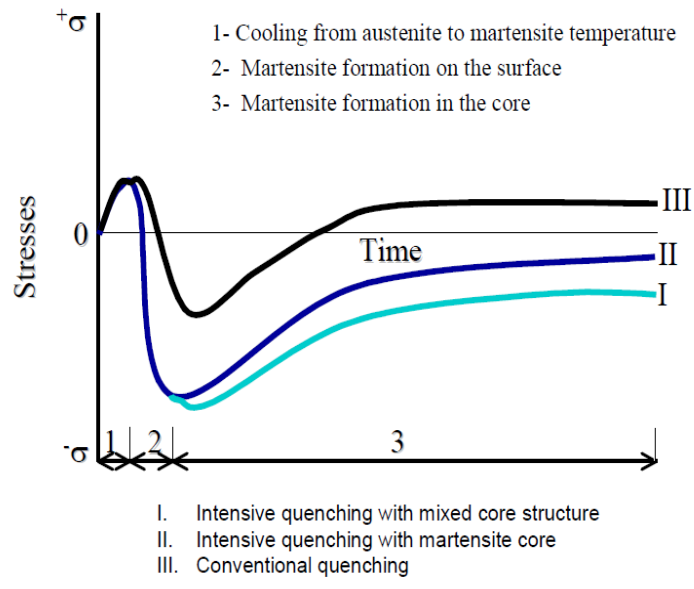

Fig. 5 Graph of surface stress vs time.

\subsection{IQ-2 Intensive Quenching Method:}

The IQ-2 technique is a three-step procedure: a) fast cooling under quenchant nucleate boiling heat transfer conditions on the part surface, b) slow cooling in the air, and c) convection cooling in the quenching tank. In IQ-2 quenching method, the duration of a sporadic film-boiling stage is minimized to avoid part cracking and distortion. This is the main reason why the plain water is not the preferred quenchant in the IQ-2 process. Various low concentrations of mineral salts in water are effectively used to eliminate film boiling and stop part corrosion. A water/salt solution eliminates film boiling as follows: The water/salt solution contains negatively charged ions. The heated part (at austenitizing temperature) is always positively charged. When the 
positively charged part is immersed into the quench tank the negative ions are attracted to the part surface. The salt ions together with quenchant flow physically destroy the vapour blanket. Note, that the quenchant flow velocity need not be as high as in IQ-3 systems. However, the agitation should be more intensive compared to conventional oil quench tanks.

During the first stage of cooling, martensite forms rapidly in the part surface layer. To avoid surface cracking in IQ-2, the fast cooling is interrupted when there is less than $50 \%$ of martensite formed in the surface layer of the part and the surface layer is still "plastic." The steel part is removed out from the quenchant. Note that the boiling point of the quenchant on the part surface should correspond to the temperature on CCT or TTT diagrams providing approximately 50\% martensite. After "interruption" of the intensive stage of cooling, the part cooling continues in the air. During this second stage of IQ-2, the part surface layer or "shell" is selftempered by the heat coming from the hot core. The part temperature equalizes throughout the cross sectional area. Also, in this second stage, the part compressive surface stresses (developed in the first stage of cooling) are fixed. As a result of the self-tempering process, the martensitic surface layer strengthens eliminating possible cracking during final stage of the IQ-2 cooling. In the third phase of the IQ-2 quench, the part is returned to the intensive quench tank for further convection cooling to complete the required phase transformations in the surface layer and in the part core.

A shortcoming of the IQ-2 method is that the water/salt solution boiling temperature does not always coincide with the martensite finish temperature of the alloy. To avoid this shortcoming, an IQ-3 intensive quenching process was proposed.

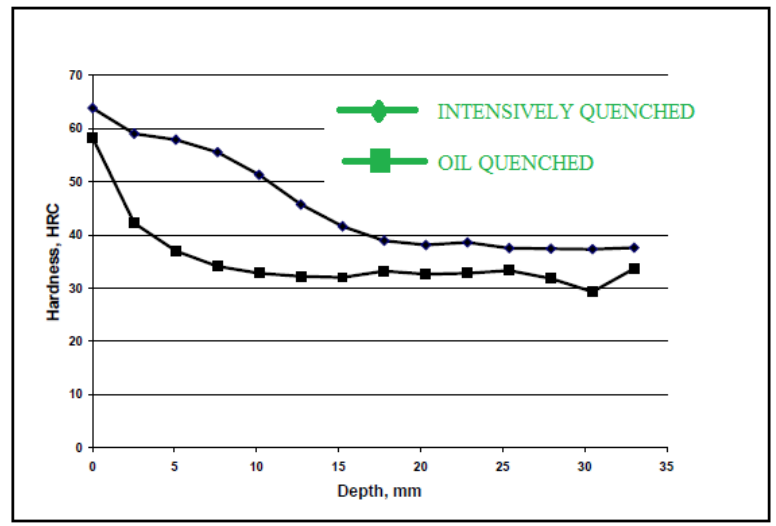

Fig. 6 Graph of hardness vs depth [6].

\subsection{IQ-3 Intensive Quenching Method:}

IQ-3 is the most intensive and best hardening method in terms of creating high compressive surface stresses, to an optimum depth; IQ-3 yields the highest amount of "super strengthening" of the part for a given material or alloy. Simply stated IQ-3 gives the most "bang for the buck." IQ-3 involves one-step "intensive" cooling in contrast to the multistep cooling rates of the IQ-1 and IQ-2 processes. When the IQ-3 process is applied, part surface cooling is so fast that both the film boiling and nucleate boiling are completely avoided and the basic heat transfer mode on the part surface is simply convection. Therefore "direct convection cooling" is the first key element to the IQ-3 process. In the IQ-3 method, intensive cooling is continuous and uniform over the entire part surface until compressive stresses on the part surface reach their maximum value and optimal depth depending on part geometry. These maximized compressive surface stresses will be diminished if the core of the part is cooled further, to the quenchant temperature. Therefore, the second key element of the IQ-3 process is to interrupt intensive cooling at the proper time - when compressive surface stresses are at their maximum value and to the optimum depth.

In practice there are three major issues to implementation of the IQ-3 quenching method. The first one is that it is not always possible to provide a high-velocity water flow uniformly around the entire part surface area. This is especially difficult to do for a part with complex geometry. The second limitation relates to quenching of relatively thin parts with the thickness of less than about $1 / 4$ ". With such thin parts it is very difficult to provide a proper temperature gradient within the part to get a $100 \%$ martensitic structure in the part surface layer, and, at the same time have an austenitic core that will convert to a hardened intermediate structure in the part core. For thin parts, the required high water flow velocity and the short time to "interruption" become in many cases impractical. Finally, IQ-3 method is not as adaptable to batch quenching of steel parts since it is practically impossible to provide high water flow velocity and uniformity throughout the entire batch. To quench intensively parts of complex shape, thin parts or parts in batches, the above IQ-2 quenching technique should be used. However, parts of thick cross-sections (more than $3 / 4$ ") and parts of relatively simple geometry 
are ideal candidates for IQ-3 quenching [6]. The depth and hardness for Intensive and oil quenching can be correlated from Fig. 6, Table II and III.

Table II Comparison between oil and intensive quench.

\begin{tabular}{|c|c|c|c|}
\hline \multirow{2}{*}{ Quench } & \multicolumn{3}{|c|}{ Hardness, HRC } \\
\cline { 2 - 4 } & $\begin{array}{c}\text { 40Cr* (AISI } \\
\text { 140) M10 Bolt }\end{array}$ & $\begin{array}{c}\text { 4037 M18 } \\
\text { Bolt }\end{array}$ & $\begin{array}{c}\mathbf{5 1 6 0 H} \\
\text { Bar }\end{array}$ \\
\hline Oil & 42.7 & $51-47$ & 60.4 \\
\hline Intensive & 54.8 & $58-60$ & 63.4 \\
\hline
\end{tabular}

Table III Sprocket tested by both methods.

\begin{tabular}{|c|c|c|c|}
\hline \multirow{2}{*}{ Quench } & \multicolumn{2}{|c|}{ Hardness, HRC } & Hardened Depth, \\
\cline { 2 - 3 } & Surface & Core & Inch \\
\hline Intensive & 52 & 50.2 & Hardened through \\
\hline Oil & 50 & 36.5 & $1 / 8$ " \\
\hline
\end{tabular}

Bearing cages that were carburized for only 50\% of a standard carburization depth and intensively quenched have a better hardness profile than the same bearing cages that were carburized to $100 \%$ of the specification depth and quenched in oil per the standard production practices [7].

\section{Electromagnetic processing for microstructure modification.}

Magnetic field, especially high magnetic field, as clean, powerful and non-contacting energy, has received much attention in materials research area, as it can act on atomic behaviours, affect such as atom arrangement, matching and migration and hence exert powerful influence on microstructures and properties of materials.

For ferrous alloys with phase transformations, the final strengthening results from the transformation from austenite to martensite. The amount of martensite obtained from the transformation directly affects the strengthening effect. As austenite is paramagnetic and martensite is ferromagnetic, the introduction of the applied magnetic field will certainly promote the transformation and thus enhance the effect of strengthening. Therefore, applying magnetic field to heat treatment started from quenching process in the late 50s and the 60s last century .Like temperature or pressure, the magnetic field is one of the important thermodynamic parameters that are used to change the internal energies of materials. In the case of transformation from austenite to martensite, the Gibbs free energy of martensite would be greatly lowered as it has higher magnetization compared with that of austenite.

As the magnetic field can accelerate the transformation and enhance the amount of martensite obtained, the related properties are increased. The possible reasons for the effect of the impulse magnetic field could be summarized as : (1) magnetic field increases the transformation driving force and thus enhances the transformation; (2) the magnetostrictive effect under the impulse magnetic field causes the interspacing between $\mathrm{Fe}$ atoms to change periodically that enhances diffusion of carbon atoms and decreases their diffusion activation energy and thus promotes the transformation; (3) the magnetic field lowers the internal energy of the ferromagnetic phase and thus decreases nucleation barrier and increases the nucleation rate. In this way, the magnetic field shows positive influence on improving the mechanical properties of the conventional materials.

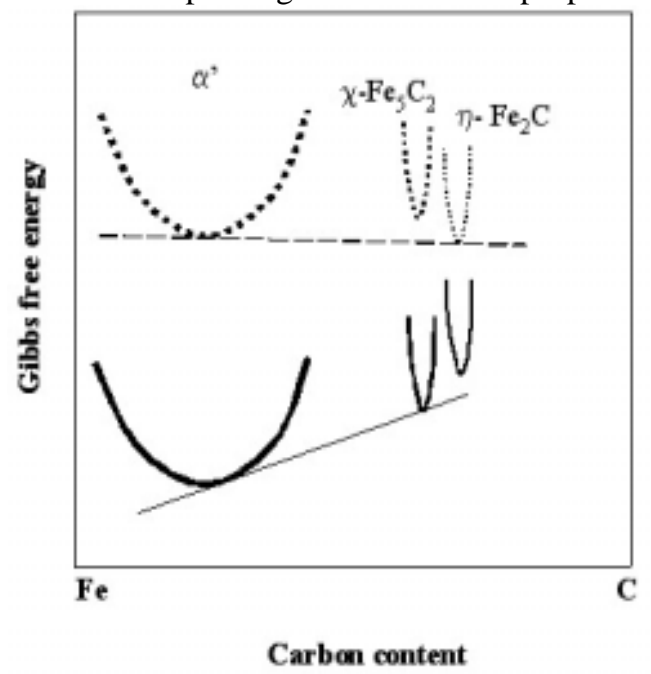

Fig. 7. Gibbs free energy versus carbon content 
The magnetic field has strong thermodynamic and kinetic effects on transformations between phases with different saturation magnetizations. When it is applied to a transformation from a low magnetization phase to a high magnetization phase, as in the case from austenite to martensite, bainite or ferrite, it enhances the transformation temperature, accelerates the transformation speed and increases the amount of the product phase. These effects could be applied to shorten the heat treatment time, increase productivity and thus innovate the conventional heat treatment processes.

Moreover the magnetic field can obviously retard the recovery progress of the ferrite matrix through hindering grain boundary migration by magnetic ordering and domain walls. In the specific case of low temperature tempering, the magnetic field can change the precipitation sequence of transition carbides by changing their Gibbs free energies through magnetization and hence improve the impact toughness of the material [8].

\section{Heat Treatment Future In 2020}

The future of heat treatment is very bright and hence development in it is at a rapid speed. In mere future that is in the year 2020 some drastic change in technology of heat treatment would occur resulting in innovation of energy efficient, cost effective, environmental friendly process and materials. In 2020 following points will be achieved:

- Reduction in production cost by $75 \%$.

- Increase in furnace life by 10 fold

- Reduction in price of furnace by $50 \%$.

- Reduction in energy consumption by $80 \%$.

- Achieve zero distortion and maximum uniformity in heat treated process.

- Development of hybrid natural gas/electric heating system to minimize energy cost.

- Development of steels for induction that permits even faster processing times.

- Development of materials suitable for rapid heating technologies [9].

\section{Conclusions}

Challenges towards the development of design and production technologies of light, durable and environmental friendly materials will proceed further and competition in material seems to become more severe. In spite of the existing well used heat treatment processes, there is possibility to increase energy and processing efficiency, and improve product quality by the development of advanced processing methods. To meet and overcome these challenges we must think in this way that "All innovations are built on rejections". An innovation is one of those things that society looks at \& says, if we make this part of the way we live $\&$ work, it will change the way we live \& work. Hence concluding that though there are various hurdles in the path of success but heat treatment in 2020 will be at its milestone.

\section{References}

[1]. K. Funtani, "Emerging technology in heat treatment and surface engineering of automotive components", IFHTSE conference, 2009.

[2]. Daniel Herring, Frederick J. Otto, “Low-pressure vacuum carburising”, Midwest thermal -vac Kenosha, 2009 (online). Available: http://www.heat-treat-doctor.com.

[3]. Daniel Herring, "Technology trends in vacuum heat treating ,part three: new technology and future developments" ,Midwest thermal -vac Kenosha, January 2009(online). Available: http://www.heat-treat-doctor.com.

[4]. Donald Jordan, "Vacuum gas nitriding furnace produces precision nitrided parts" ,ASM Heat treating society, September 2009 [online]. Available: http://www.asminternational.com

[5]. Daniel Herring, Frederick J. Otto , "Low-pressure vacuum carburising”,Midwest thermal -vac Kenosha,2009 (online). Available: http://www.heat-treat-doctor.com.

[6]. N.I.Kobasko, M.A.aronov, J.A.Powell , L.C.F. Canale ,G.E.Totten, "Improved production of automotive parts by intensive quenching processing", $2^{\text {nd }}$ international conference on Heat treatment and surface engineering in automotive applications, pp 1322, 20-22 June 2005

[7]. Daniel Herring, "Technology trends in vacuum heat treating, part one:markets,processes and applications", Midwest thermal -vac Kenosha,2008(online).Available: http://www.heat-treat-doctor.com.

[8]. Y.Zhang, X.Zhao, L.Zuo, C. Esling, "Innovation of conventional heat treatment and microstructural modification of steels by electromagnetic processing”, International Conference on super high strength steels, Rome, pp 61-66,2-4 November 2005.

[9]. George E. Totten, "Heat treating in 2020: what are the most critical issues and what will be the future look like?" International Federation of Heat Treatment and surface engineering, 2011. 